\title{
BMJ Open Prevention versus early detection for long-term control of melanoma and keratinocyte carcinomas: a cost- effectiveness modelling study
}

\author{
Louisa Gordon (10 , ${ }^{1,2,3}$ Catherine Olsen (1) , ${ }^{4}$ David C Whiteman, ${ }^{3,4}$ \\ Thomas M Elliott, ${ }^{1}$ Monika Janda, ${ }^{5,6}$ Adele Green ${ }^{1,7}$
}

To cite: Gordon L, Olsen C, Whiteman DC, et al. Prevention versus early detection for long-term control of melanoma and keratinocyte carcinomas: a cost-effectiveness modelling study. BMJ Open 2020;10:e034388. doi:10.1136/ bmjopen-2019-034388

- Prepublication history and additional material for this paper are available online. To view these files, please visit the journal online (http://dx.doi org/10.1136/bmjopen-2019034388).

Received 18 September 2019 Revised 29 January 2020 Accepted 07 February 2020
D) Check for updates

(c) Author(s) (or their employer(s)) 2020. Re-use permitted under CC BY-NC. No commercial re-use. See rights and permissions. Published by BMJ.

For numbered affiliations see end of article.

\section{Correspondence to} Dr Louisa Gordon; Louisa.Gordon@qimrberghofer. edu.au

\section{ABSTRACT}

Objective To compare the long-term economic impact of melanoma prevention by sun protection, with the corresponding impact of early detection of melanoma to decrease melanoma deaths.

Design Cost-effectiveness analysis using Markov cohort model. Data were primarily from two population-based randomised controlled trials, epidemiological and costing reports, and included flow-on effects for keratinocyte cancers (previously non-melanoma skin cancers) and actinic keratoses.

Setting Queensland, Australia.

Participants Men and women with a mean age 50 years modelled for 30 years.

Interventions Daily sunscreen use (prevention) compared with annual clinical skin examinations (early detection) and comparing these in turn with the status quo.

Primary and secondary outcomes Costs, counts of melanoma, melanoma deaths, keratinocyte cancers, life years and quality-adjusted life years.

Results Per 100000 individuals, for early detection, primary prevention and without intervention, there were 2446, 1364 and 2419 new melanomas, 556, 341 and 567 melanoma deaths, 64 452, 47682 and 64659 keratinocyte cancers and $£ 493.5, £ 386.4$ and $£ 406.1$ million in economic costs, respectively. There were small differences between prevention and early detection in life years saved $(0.09 \%)$ and quality-adjusted life years gained $(0.10 \%)$. Conclusions Compared with early detection of melanoma, systematic sunscreen use at a population level will prevent substantial numbers of new skin tumours, melanoma deaths and save healthcare costs. Primary prevention through daily use of sunscreen is a priority for investment in the control of melanoma.

\section{INTRODUCTION}

Melanoma is a major public health burden in many fair-skinned populations. It is the most serious type of skin cancer and can be fatal if diagnosed at advanced stage. Globally, there are around 60100 deaths each year from melanoma, with one-quarter of these (around 15 500) occurring in the USA, the UK and Australasia. ${ }^{1}$ Other skin malignancies
Strengths and limitations of this study

- This is the first study to compare the costeffectiveness of primary prevention and early detection in the context of skin cancer.

- Melanoma diagnosis and mortality data from the Queensland Cancer Registry are considered as highly accurate and complete.

- Modelling relied on population outcomes from two randomised controlled trials that serve to minimise bias in key model inputs but indirect comparison analyses were undertaken.

- Data are scarce for health utilities of multiple keratinocyte carcinomas and benign skin tumours so proxies and small disutility values for these events were used.

- Self-reports of skin checks and sunscreen use from the QSKIN study were used and we cannot rule out responder bias.

such as basal cell carcinoma and squamous cell carcinoma (collectively called keratinocyte cancers $(\mathrm{KCs}))$ are the most common cancers in humans, associated with high costs (US $\$ 4.8$ billion in the USA in 2011) ${ }^{2}$ and lowered quality of life though rarely fatal. In addition, benign pigmented skin lesions such as nevi and solar lentigines are very common in fair-skinned individuals while actinic keratoses are common on sun-damaged skin. ${ }^{3}$ Any evaluation aimed at melanoma control will therefore need to account for the clinical management of these additional skin tumours, malignant and benign, that inevitably will be encountered in the target population.

Ultraviolet (UV) radiation from sunlight or artificial sources is the main environmental cause of melanoma, KCs and actinic keratoses. Primary prevention activities focus on educating the public to protect their skin from UV radiation using protective clothing and sunscreens, rescheduling outdoor 
activities and reducing use of indoor tanning devices. Evidence of effectiveness is strongest for sunscreen use. ${ }^{45}$ Improving sun protection behaviours requires upfront financial investment in sun safety campaigns and may be difficult in some population segments such as avid tanners and adolescents. Early detection of melanoma saves lives by diagnosing and treating tumours early before they metastasise. There may also be cost benefits in treating small KCs that are detected earlier with treatment by biopsy excision versus more expensive treatment like Mohs surgery. Two large population-based studies have shown that people who had physician skin checks in the 3 years prior to melanoma diagnosis had higher proportions of thin melanomas $(\leq 0.75 \mathrm{~mm})$ than those who had no physician skin checks. ${ }^{67}$ Thickness of melanoma is highly correlated with prognosis ${ }^{8}$ and so early detection is intuitively appealing and widely supported by dermatologists. However, early detection programmes carry the risk of overdiagnosis and unnecessary treatments because skin examinations increase the yield (and subsequent treatment costs) of indolent skin cancers and benign skin lesions. ${ }^{9}$ This phenomenon is well documented in screening programmes ${ }^{10} 11$ where the number of biopsies and excisions of benign skin lesions exceed confirmed skin cancers by fivefold. ${ }^{10}$ Furthermore, most leading health authorities do not endorse populationwide screening for early melanoma detection because of lack of evidence that screening reduces melanoma mortality. ${ }^{12}$

Estimating the health and economic value of early detection of melanoma on one hand, and melanoma prevention on the other, are critical for decision-making in settings of constrained health budgets, yet it appears the two strategies have never been compared. We therefore compared the relative cost-effectiveness of programmes of primary prevention of melanoma (through increases in sunscreen use) versus early detection of melanoma (through whole body clinical skin examination) with the status quo, in an Australian population over a 30 -year period.

\section{METHODS}

\section{Study population}

Our study was based on the mainly fair-skinned population of the Australian state of Queensland who experience high UV radiation levels year-round.

\section{Comparative strategies}

Three strategies were compared:

1. Primary prevention-comprising daily sunscreen use.

2. Early detection-comprising whole-body skin examination by physicians.

3. No intervention-no dedicated early detection or primary prevention programmes for melanoma or other skin cancers.

The no intervention strategy represents the general population in Queensland with prevailing levels of sunscreen use and skin examinations (including opportunistic skin checks by family physicians) as reported from the QSKIN Sun and Health Study ${ }^{13}$ (see online supplementary figure 1). These behaviours are reflected in the costs and outcomes of this modelled strategy. The expected links between strategy and outcomes are illustrated in figure 1. In the absence of long-term skin checking behaviours, we assumed that clinical skin examinations in the early detection scenario remained constant over time and applied equally to men and women over 50. Clinical skin examinations were assumed to be undertaken annually and reflect prevailing clinical competencies and use of dermoscopy. The incidence of new skin cancers remained elevated in the early detection arm with yearly clinical skin examinations as shown over successive years in a 10-year community sample. ${ }^{14}$ We also assumed that regular sunscreen use remained constant over time, as supported by trial evidence. ${ }^{15}$ Both the early detection and primary prevention arms represent $100 \%$ of individuals receiving skin examinations or using sunscreen, respectively, although their consequent outcomes are based on pragmatic trial evidence where additional background protective behaviours might have occurred. 


\section{Trial evidence}

For the primary prevention strategy, we used available data from the community-based Nambour Skin Cancer Prevention Trial $(\mathrm{n}=1621)$ that evaluated daily application of sun protection factor (SPF) $15+$ sunscreen to face, arms and hands versus discretionary use of sunscreen for skin cancer prevention. Skin cancer outcomes were monitored by dermatological examinations for the first 5 years and then through record linkage to histopathology reports for 15 years. ${ }^{45}$ Trial results showed the effect of daily sunscreen use on incidence of invasive and non-invasive melanomas (HR $0.50,95 \%$ CI 0.24 to 1.02$)^{4}$ and squamous cell carcinomas (HR 0.65, 95\% CI 0.45 to $0.94)^{5}$ at 5 years. Routine sunscreen use was sustained in people randomised to the regular application group 12 years after the trial ended. ${ }^{15}$ The main study limitation is that the results are directly relevant to people living in sunny climates with high ambient sun exposure; however, they will have implications for white people travelling to sunny places for holidays. ${ }^{4}$

For the early detection strategy, data from the Skin Awareness Trial ${ }^{16}$ for men over 50 years were used. This scenario modelled the increase in skin examinations in men and women aged over 50 years. The trial randomised 929 male participants selected randomly from the population-based Electoral Roll (enrolment is compulsory) to intervention or control arm. ${ }^{17}$ The intervention group received comprehensive educational materials about skin self-examination and the importance of consulting the family doctor for lesions of concern. ${ }^{16}$ The control group received an information brochure only. Histopathology reports of skin cancers and benign lesions were obtained at 12 months only. ${ }^{16}$ We estimated long-term survival using population data of melanoma thickness. ${ }^{6}$ Trial results showed increased skin selfexaminations in the intervention group $(35.3 \%)$ versus in the control group (27.2\%). ${ }^{16}$ For lesions that were managed by physicians, there was a higher proportion of malignant lesions in the intervention group (60\%) versus in the control group $40 \% .{ }^{16}$ The key limitation of this study is that men were relatively more skin aware at baseline (no differences between randomised arms) and not all participants gave permission for the researchers to contact their physicians $321 / 540(59.4 \%){ }^{16}$

\section{Model structure}

A Markov health state transition cohort model was constructed in TreeAge Pro for Healthcare 2019 (TreeAge Software, Williamstown, Massachusetts, USA) (figure 2). The model prospectively tracked the expected consequences of occurrences and sequelae of new skin lesions. The health states included: (1) melanoma (in situ; 'thin' ( $\leq 1 \mathrm{~mm}$ thickness); 'thicker' (>1 mm); (2) undetected melanoma; (3) KCs; (4) undetected KCs; (5) benign skin lesions; (6) undetected benign lesions; (7) lesion-free and (8) postdiagnosis, thin melanoma; (9) postdiagnosis, thicker melanoma; (10) melanoma deaths and (11) other deaths. Melanomas were categorised into $\leq 1 \mathrm{~mm}$ and $>1 \mathrm{~mm}$ Breslow thickness to enable a parsimonious model structure but weighted values for survival and costs reflect the specific stage differences. The model had annual cycles and the cohort could move between health states when they faced different probabilities of developing skin cancers or skin lesions or they could remain in the same state (eg, lesion-free). Some people developed multiple skin cancers and benign lesions and risk increased with age. Despite the competing risks of different skin cancers, coherence was maintained with probabilities totalling less than 1.0 in the model branches. The model tracked the cohort (mean age 50 years (SD 9)) from inception through the next 30 years. Death from melanoma ${ }^{18}$ including from advanced melanoma, ${ }^{19}$ another skin cancer or other causes ${ }^{20}$ could occur at any time.

\section{Model inputs and sources}

Model inputs and sources are provided in table 1 and the online supplementary file with more detailed information on calculations (eg, weighted means, rate to probability conversions) and background data. Briefly, from the Nambour trial, we estimated the effect of daily

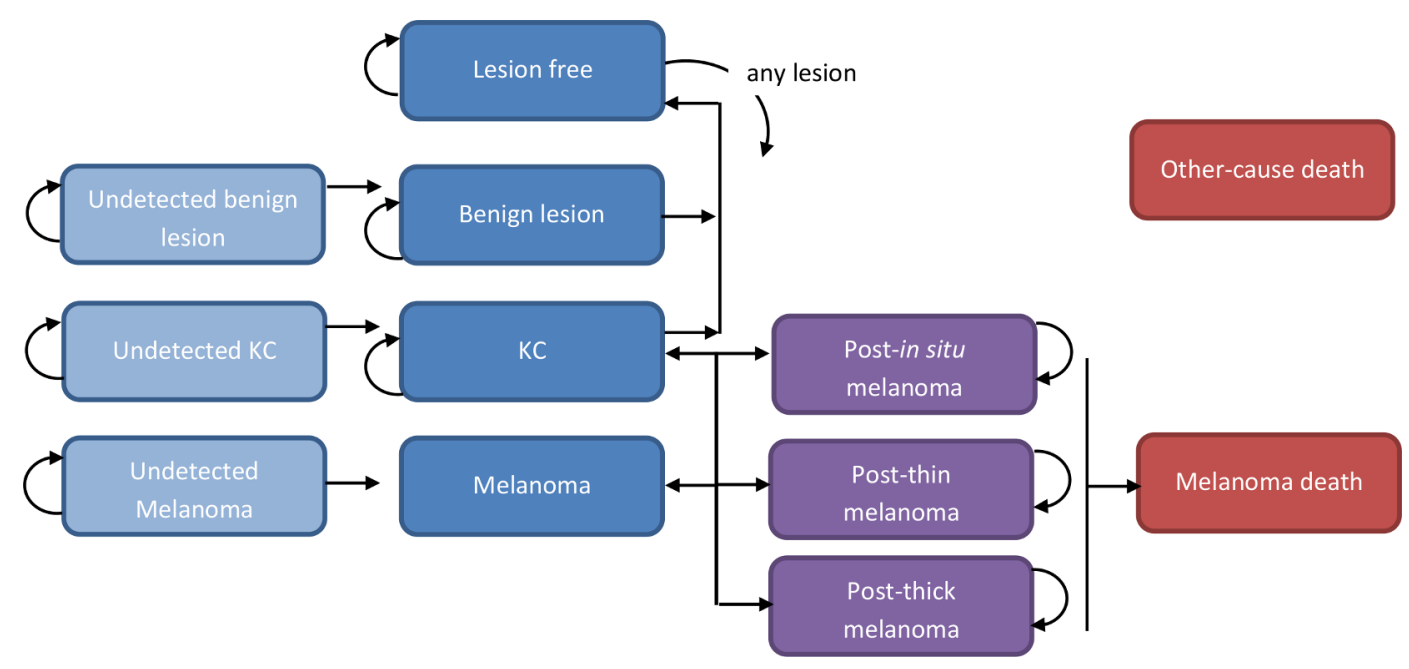

Figure 2 Illustration of the model. KC, keratinocyte cancer. 


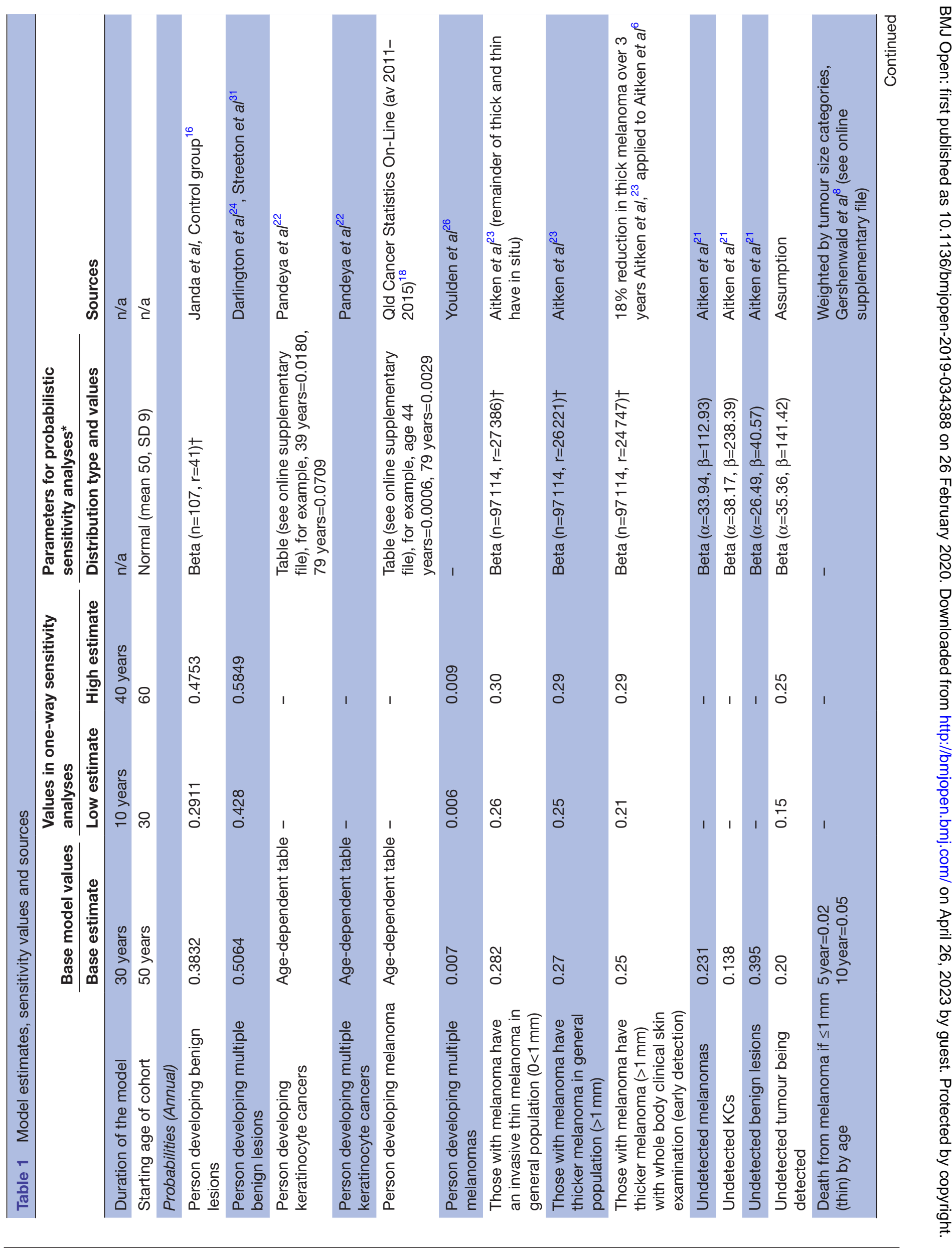




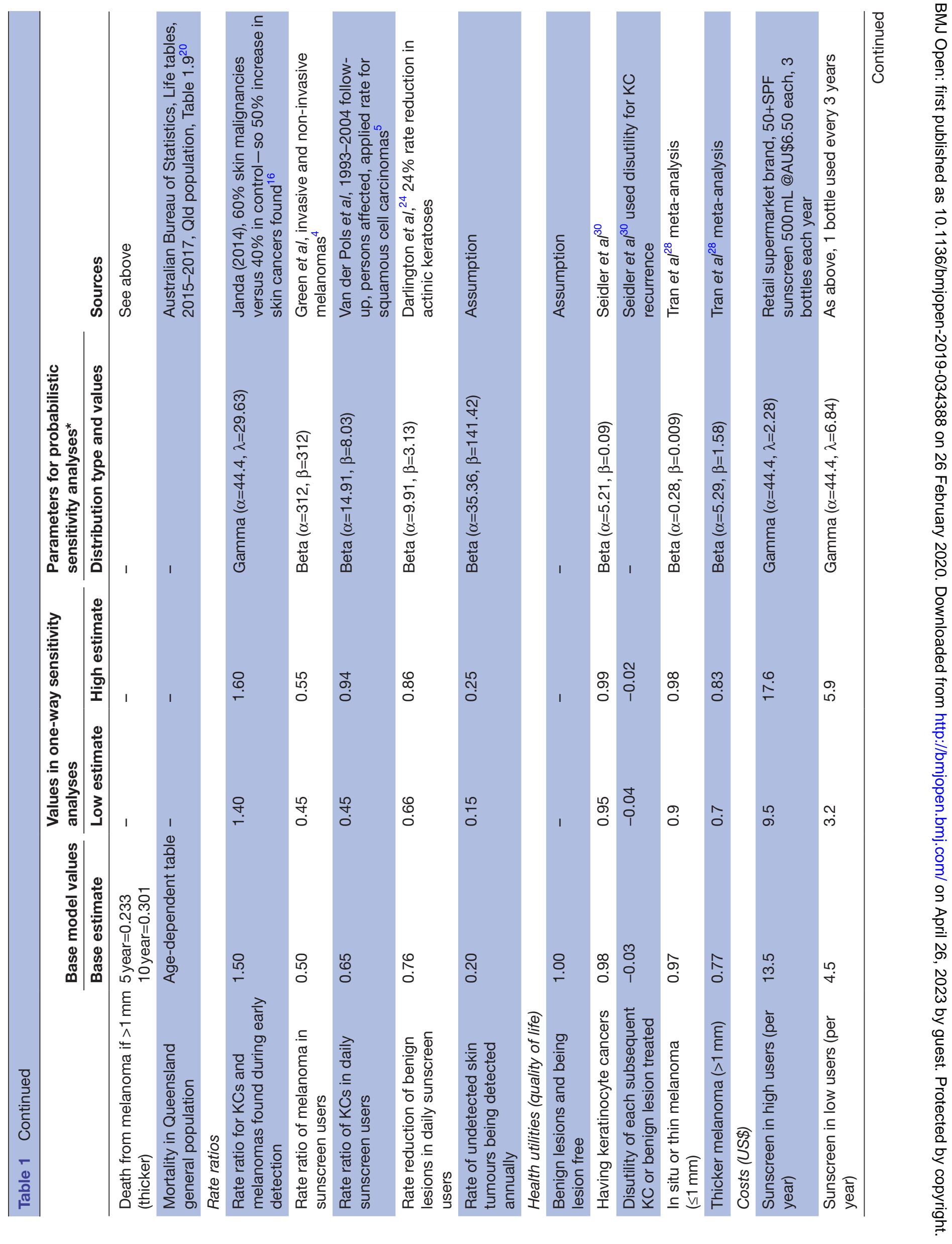




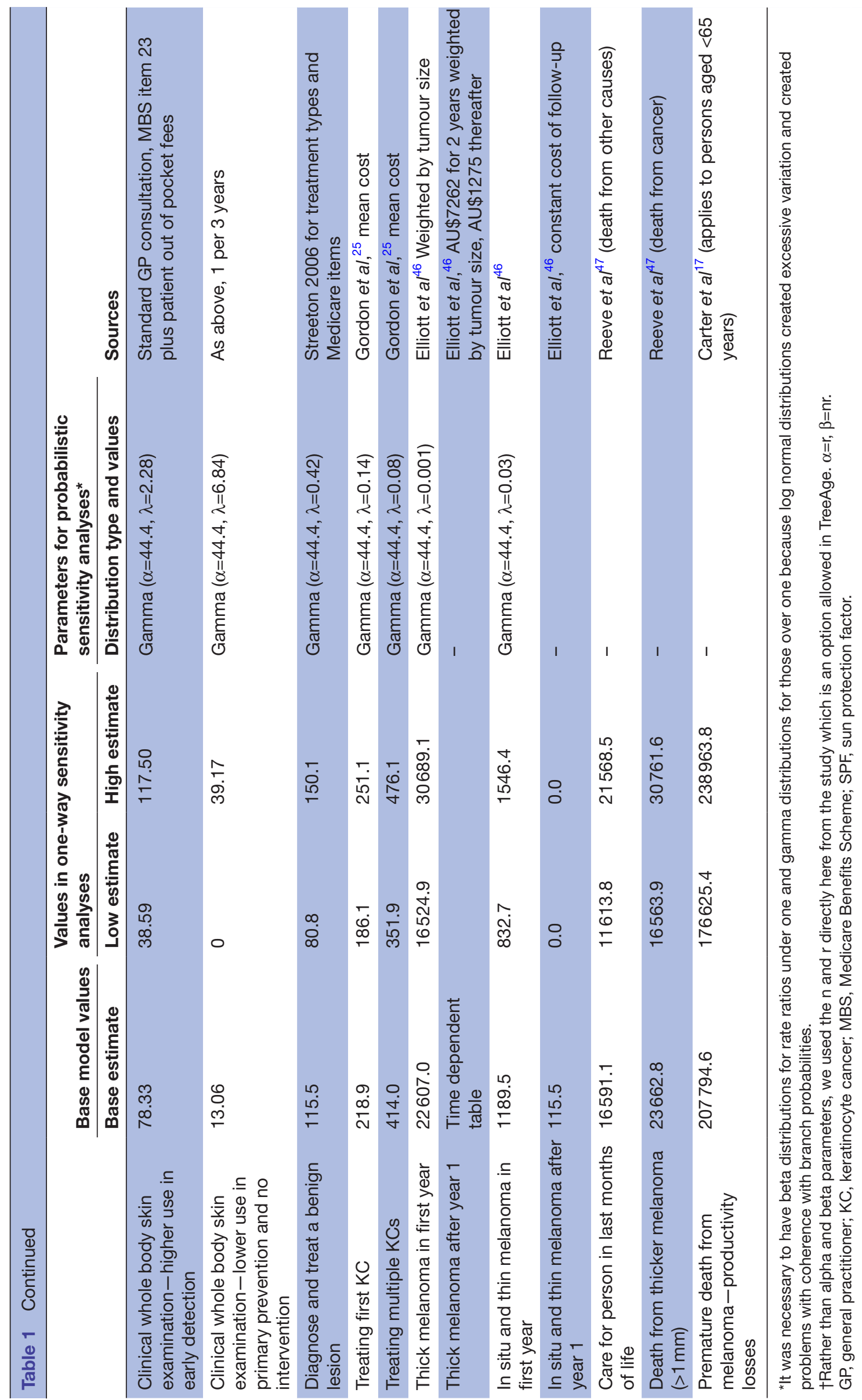

\begin{tabular}{l} 
W \\
3 \\
0 \\
0 \\
0 \\
\hline
\end{tabular}

ज

듬 
sunscreen use on incidence of invasive and non-invasive melanomas (HR $0.50,95 \%$ CI 0.24 to 1.02$)^{4}$ and squamous cell carcinomas (HR $0.65,95 \%$ CI 0.45 to 0.94$)^{5}$ (latter used for 'KCs' health state). We estimated longterm survival using population data of melanoma thickness. ${ }^{6}$ Undetected skin tumours were estimated from a pilot melanoma screening trial in Queensland involving 16383 skin examinations and showed numbers of suspicious lesions that were histopathologically confirmed as skin tumours (23\% melanoma, $14 \% \mathrm{KCs}$ and $40 \%$ benign tumours). ${ }^{21}$

Transition probabilities unrelated to interventions. In each annual cycle, a proportion of people will either continue to live without skin cancer or develop melanoma, $\mathrm{KC}$ or other skin lesions. The risks of developing skin cancer increase with age. Incidence of KCs was based on the QSKIN study and observed excisions of at least one $\mathrm{KC}$ during 2011-2014 by age-group. ${ }^{22}$ Once treated, individuals can develop subsequent skin cancers, other skin lesions or remain 'lesion-free'. Based on data from the Queensland Cancer Registry from 1995 to $2014,{ }^{23}$ the proportions of in situ (45\%), thin $\leq 1 \mathrm{~mm}$ melanomas $(28 \% \%)$ and thicker $>1 \mathrm{~mm}$ melanomas $(27 \%)$ were applied in the model. Probabilities for subsequent multiple skin lesions and tumours were based on Queensland studies. ${ }^{22}$ 24-26 Incidence of multiple invasive melanomas was available from Youlden et $a l^{26}$ For subsequent melanomas, the thickness distribution (and associated mortality) of melanomas for individuals with multiple melanomas was the same for singular melanomas. ${ }^{27}$ Mortality rates for thin melanomas were extracted from the latest survival data from melanoma from worldwide data $(n>46000) .{ }^{8}$ Health utility scores for melanoma stages, including patients with advanced melanoma receiving targeted therapies, were obtained from a meta-analysis (table 1 ) ${ }^{28}$ Robust evidence on health utilities for patients with $\mathrm{KC}$ or benign skin lesions is limited, but there is an appreciable quality of life effect where some individuals face disfiguring, multiple cancers, anxiety and other symptoms. ${ }^{29}$ From Seidler $e t a l$, we assigned a utility score of 0.984 to patients with KCs ( 0.95 and 0.99 in sensitivity analysis) and a utility reduction of -0.03 each time an individual had an additional KC. ${ }^{30}$

The study took a societal perspective and included health provider resources, consumer expenses for sunscreen and copayments for medical treatments and productivity losses to society for each premature melanoma death. ${ }^{17}$ We included the costs of a primary prevention campaign at AU $\$ 0.35$ per capita which was conservatively twice that of recent funding for a skin awareness campaign awarded in Western Australia. Healthcare costs included family physician visits for skin checks, specialist visits, pathology and treatments for melanomas, KCs and benign lesions (ie, cryotherapy, excision, topical creams). ${ }^{31}$ Resources were valued using those reported in the literature or national price schedules, inflated to 2018 Australian dollars and converted into UK pounds (AUD1.444=US $\$ 1.0=£ 0.713$ using purchasing power parities).

\section{Analyses}

The main outcomes of interest were counts of melanomas (in situ, thin $\leq 1 \mathrm{~mm}$ and thicker $>1 \mathrm{~mm}$ ), melanoma deaths, KC counts, healthcare costs, survival (life years) and quality-adjusted life years (QALYs). Mean costs, QALYs and all other outcomes for the three strategies were calculated with Monte Carlo simulation analysis and presented per 100000 persons. Future costs and QALYs were discounted at $3 \%$ per year to provide present values. We calculated incremental cost-effectiveness ratios to compare the strategies: the difference in mean costs for two strategies divided by the difference in mean QALYs. Probability distributions for each parameter were assigned using the $95 \%$ CIs (if available) or $\pm 15 \%$ of the base value (table 1). We conducted one-way sensitivity analyses in which each model input was varied between high and low values (online supplementary figure 2 ). Scenarios were performed for different durations (10-50 years), starting ages (30-60 years) and removing discounting. Results of the base case probabilistic sensitivity analysis using Monte Carlo simulation and 5000 iterations at random were presented in an incremental cost-effectiveness scatterplot. As a benchmark for cost-effective healthcare in Australia, ${ }^{32}$ a threshold of AU $\$ 50000$ per QALY gained was used. We validated the model by running internal coherence checks, checked all inputs with two modellers and assessed predicted outcomes with external reports. Best-practice guidelines for health economic modelling $^{33} 34$ were adhered to.

\section{Patient and public involvement}

The research study did not involve any direct patient and public involvement.

\section{RESULTS}

For the next 30 years where no intervention occurs, it was predicted that for every 100000 persons, 2419 melanomas, 567 melanoma deaths and 64659 KCs will occur (table 2). Furthermore, 2.6million life years, 1.8 million QALYs and £406.1 million in economic costs were predicted (table 2). This compares with the 30-year outcomes of a primary prevention strategy of 1055 fewer melanomas, 226 fewer melanoma deaths, 16977 fewer KCs, 1736 additional QALYs and $£ 19.7$ million savings in societal costs (table 2). Conversely, for the early detection strategy compared with no intervention, there would be an estimated 21 melanomas (previously undetected), 793 additional KCs, 6 fewer QALYs and cost an additional $£ 87.4$ million (table 2 ). With early detection, diagnosing melanomas that were previously undetected is a positive finding leading to lower-risk cancers but health utility decrements accrue for all melanomas and KCs and the higher numbers of early stage cancers and KCs for resulted in slightly fewer overall QALYs than the no intervention strategy. Primary prevention was superior to early detection across most outcomes but at the expense of 21 undetected melanomas per 100000 and produced small 
Table 2 Projected health and economic outcomes over 30 years (mean per 100000 persons) by strategy

\begin{tabular}{|c|c|c|c|c|c|c|}
\hline & $\begin{array}{l}\text { Early } \\
\text { detection }\end{array}$ & $\begin{array}{l}\text { Primary } \\
\text { prevention }\end{array}$ & No intvn & $\begin{array}{l}\text { Primary versus } \\
\text { ED difference }\end{array}$ & $\begin{array}{l}\text { ED versus } \\
\text { no intvn } \\
\text { difference }\end{array}$ & $\begin{array}{l}\text { Primary versus } \\
\text { no intvn } \\
\text { difference }\end{array}$ \\
\hline \multicolumn{7}{|l|}{ Number of melanomas } \\
\hline \multirow[t]{2}{*}{$A / l^{\star}$} & 2446 & 1364 & 2419 & -1082 & 27 & -1055 \\
\hline & & & & $-44.2 \%$ & $1.1 \%$ & $-43.6 \%$ \\
\hline In situ melanomas* & 1133 & 601 & 1074 & -531 & 59 & -473 \\
\hline \multirow{2}{*}{$\begin{array}{l}\text { Thin melanomas } \\
(0 \leq 1 \mathrm{~mm})^{\star}\end{array}$} & 690 & 379 & 676 & -311 & 14 & -298 \\
\hline & & & & $-45.1 \%$ & $2.0 \%$ & $-44.0 \%$ \\
\hline \multirow{2}{*}{$\begin{array}{l}\text { Thick melanomas } \\
(>1 \mathrm{~mm})^{*}\end{array}$} & 623 & 362 & 647 & -261 & -24 & -285 \\
\hline & & & & $-41.8 \%$ & $-3.7 \%$ & $-44.0 \%$ \\
\hline $\begin{array}{l}\text { Number of deaths from } \\
\text { melanoma* }^{*}\end{array}$ & & & & $-38.7 \%$ & $-1.9 \%$ & $-39.9 \%$ \\
\hline \multirow{2}{*}{$\begin{array}{l}\text { Number of excised } \\
\text { keratinocyte cancers }\end{array}$} & 65452 & 47682 & 64659 & -17770 & 793 & -16977 \\
\hline & & & & $-27.2 \%$ & $1.2 \%$ & $-26.3 \%$ \\
\hline \multirow[t]{2}{*}{ Societal costs (£million) } & $£ 493.5$ & $£ 386.4$ & $£ 406.1$ & $-£ 107.1$ & $£ 87.4$ & $-£ 19.7$ \\
\hline & & & & $-21.7 \%$ & $21.5 \%$ & $-4.9 \%$ \\
\hline \multirow[t]{2}{*}{ QALYs } & 1821195 & 1822937 & 1821201 & 1742 & -6 & 1736 \\
\hline & & & & $0.10 \%$ & $0.00 \%$ & $0.10 \%$ \\
\hline \multirow[t]{2}{*}{ Life years* } & 2635444 & 2637734 & 2635396 & 2290 & 49 & 2338 \\
\hline & & & & $0.09 \%$ & $-0.00 \%$ & $0.09 \%$ \\
\hline
\end{tabular}

*Undiscounted.

ED, early detection; intvn, intervention; QALYs, quality-adjusted life years.

differences in life years $(0.09 \%)$ and QALYs $(0.10 \%)$ (table 2, online supplementary figures 3-5). Compared with primary prevention, early detection cost an additional £107.1 million (22\%) to society, and there were 531 $(47 \%)$ more in situ melanomas, $311(45 \%)$ more thin melanomas and $261(42 \%)$ more thicker melanomas per 100000 persons (table 2).

Regarding incremental cost per QALY ratios, one-way sensitivity analyses showed the most important model inputs were unit cost of skin examinations (range $£ 27.52-£ 83.78)$; probability of a melanoma being $>1 \mathrm{~mm}$ (0.21-0.29); rate reduction of benign lesions $(0.66-0.86)$ and health utility of KCs (0.95-0.99) (table 3). These variables changed the 'base-case' incremental cost per QALY ratio for primary prevention versus early detection between $-£ 185000$ and $-£ 31000$ but the overall finding that primary prevention incurred lower costs but higher QALYs than early detection remained unchanged. If the mortality probability of thick melanoma $(>1 \mathrm{~mm})$ at 5 years $(0.233)$ and 10 years $(0.301)$ was lowered to 0.19 and 0.26 , respectively, effect was small and more in favour of primary prevention (4\% improvement) (table 3 ).

When the model duration was shortened to 10 years, or separately increased to 40 years, incremental cost savings (per 100000 ) for primary prevention versus early detection were $£ 52.9$ million and $£ 116.5$ million, respectively (table 4). Reducing the starting age to 30 years and raising it to 60 years produced cost savings of $£ 112.0$ million and $£ 93.1$ million, respectively, and discounting or not, also produced large differences in costs and QALYs (table 4). The probability that primary prevention was cost effective compared with early detection was $100 \%$ (online supplementary figures 3-5). Per person mean incremental cost savings for primary prevention versus early detection were $£ 1071$ (95\% credible interval: $£ 679$ to $£ 1490$ ) and mean QALYs were 0.0174 (95\% credible interval: 0.0069 to 0.0365 ). Model validation indicated high external validity (online supplementary file).

\section{DISCUSSION}

In mid-aged people followed up for 30 years, systematic improvements in sunscreen use would prevent skin cancers and benign skin tumours and bring significant cost savings. Melanoma deaths after 30 years of regular sunscreen use would be one-third less of that after 30 years of increased clinical skin examinations. As expected with an early detection intervention, higher numbers of 


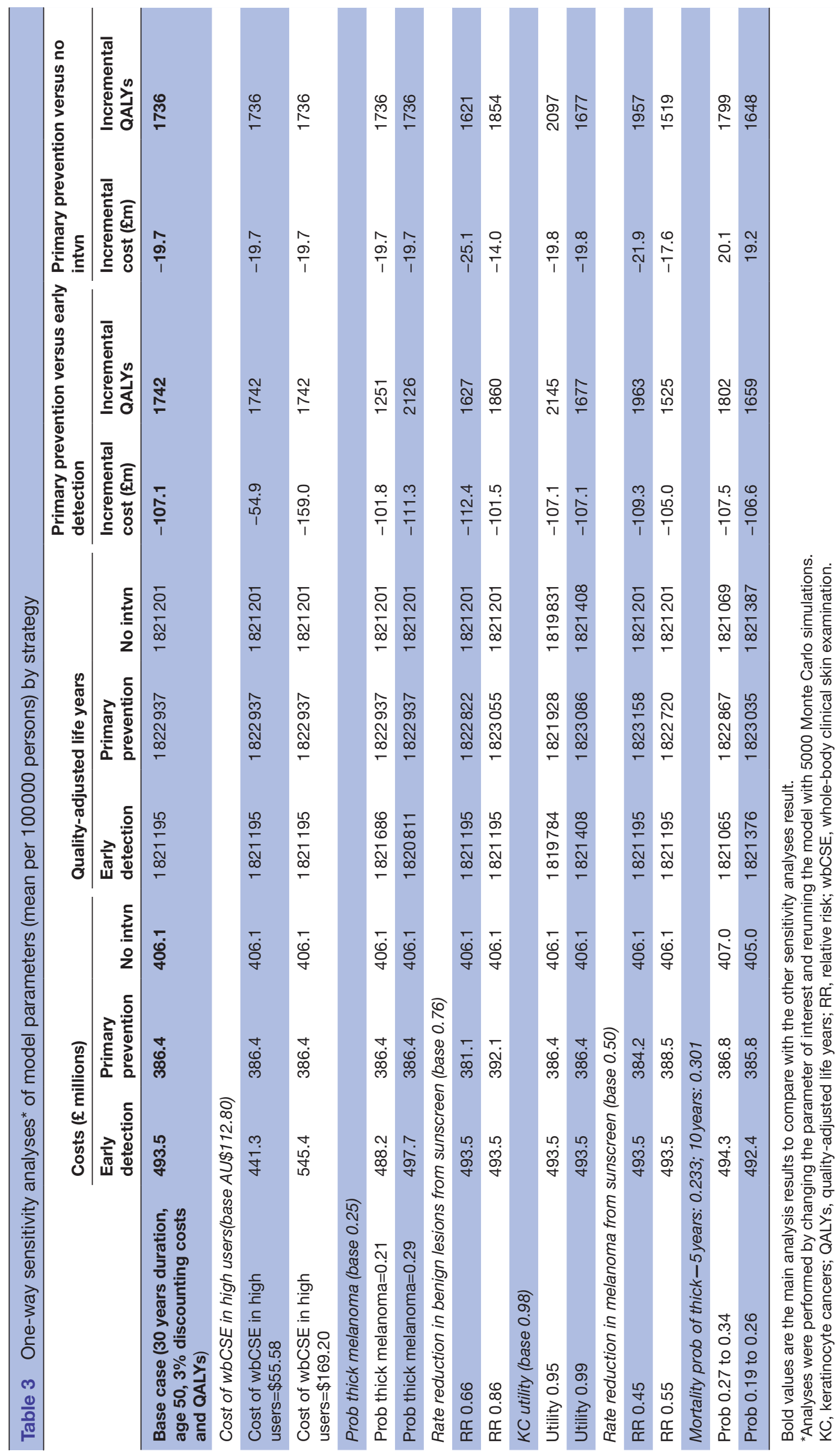




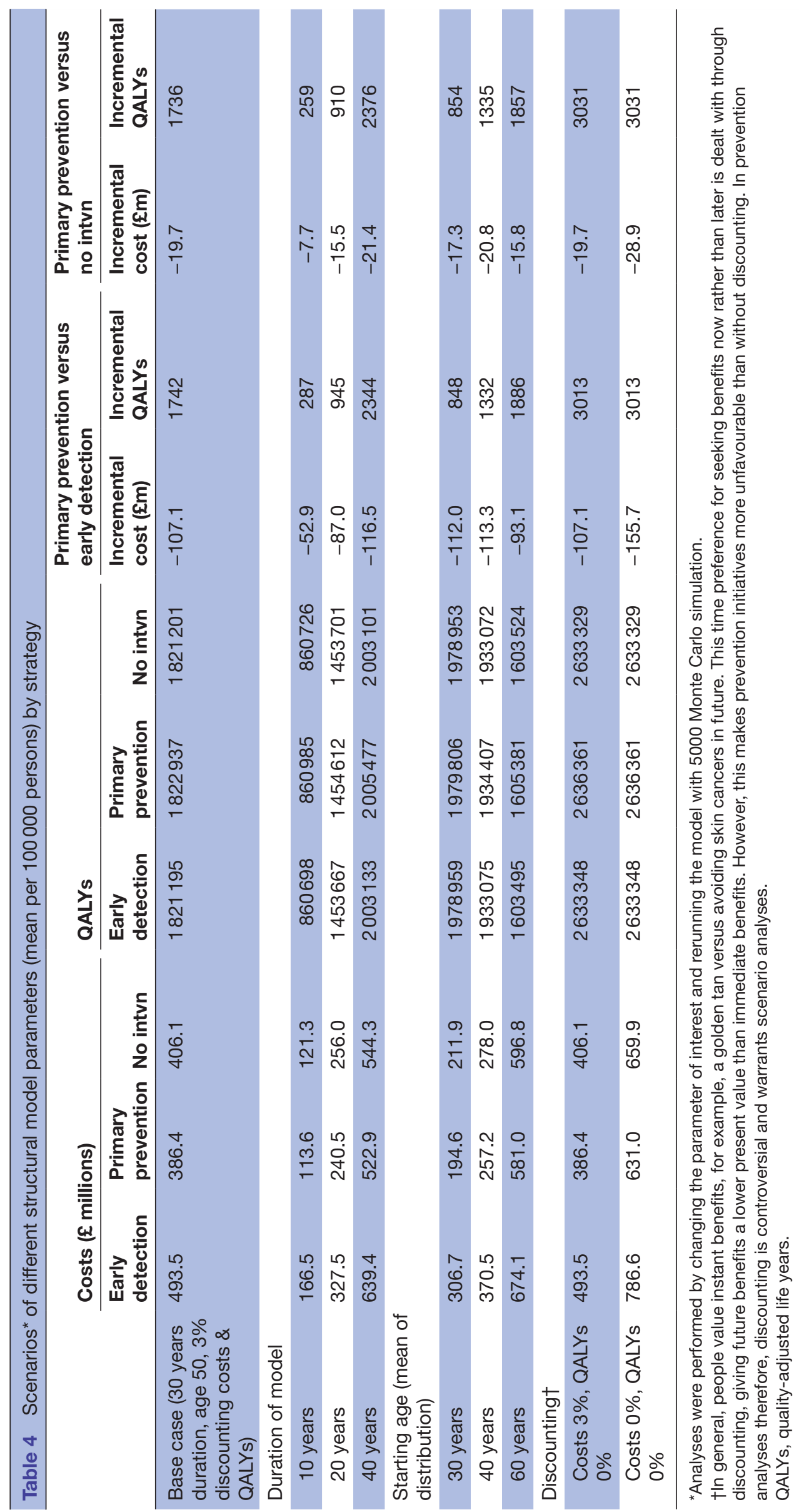


detected melanomas, KCs and all other skin lesions would be diagnosed and treated than with either the primary prevention or the no intervention scenario. Early detection was favourable in detecting early stage, treatable skin cancers; however, these higher proportions of thin melanomas presenting for medical attention did not offset the economic and quality of life burdens incurred by concurrently detecting higher numbers of KCs and benign skin lesions. Conversely, primary prevention has the dual benefits by avoiding skin cancers altogether and reducing quality of life decrements and costs relative to early detection, although some melanomas would be undetected. With the majority of melanomas routinely detected at early stages in the general population without dedicated surveillance, there is minimal impact on mortality (and therefore life years).

We compared primary prevention with early detection and a 'no intervention' baseline group but it is important to stress that the interventions were based on pragmatic trials that meant individuals could engage in their normal skin behaviours in Queensland. In earlier iterations of the model, we considered alternative behavioural scenarios but chose the current status quo (or mixed behavioural scenario reflecting real-life) with alternative best possible strategies. Although it may be unrealistic to achieve $100 \%$ compliance with protective behaviours, within a pragmatic trial with multiple behaviours possible, the strategies more correctly align with the data inputs on outcomes after these behaviours. Behaviours were not explicitly modelled but rather their consequences through rate ratios of skin cancers or thick melanomas and costs. Our use of distributions around the key estimates in the probabilistic sensitivity analyses will implicitly cover the variations in skin behaviours, costs and health-related quality of life. For example, decrements in quality of life associated with being diagnosed with a skin cancer is likely to be directly related to both treatment and psychological concerns but varies from person to person.

Eight previous economic evaluations of melanoma early detection programmes have been reported: three Australian, ${ }^{35}$ three US ${ }^{35}$ and one Belgian ${ }^{36}$ and UK. ${ }^{37}$ All studies used long-term Markov or decision-analytic models as we did, and all showed early detection producing a downshift of melanoma stage and improved survival. ${ }^{35}$ Several studies included the costs for increased case-finding of KCs and benign tumours but only recent studies recognised the importance of quality of life and used QALYs as a primary outcome. ${ }^{3638}$ Economic evaluations of primary prevention of skin cancer have varied in intervention type and duration but all have shown favourable economic and health benefits. ${ }^{35}$

In our ageing populations, mortality from melanoma competes with all-cause mortality. At a population level, the deaths of a small proportion $(\sim 5 \%)$ of people with melanoma that have advanced melanoma are somewhat diluted by deaths from other common diseases and so the gains in life years from population health strategies are elusive. Instead of population screening, screening those at known high risk of melanoma based, for example, on high numbers of nevi, or fair skin type, has been proposed..$^{39}$ Developments in imaging technologies may bring improved diagnostic accuracy given that a proportion of difficult-to-diagnose melanomas and $\mathrm{KCs}^{40}$ are liable to misdiagnosis.

We have previously shown that primary prevention via regular sunscreen use reduces economic burden. ${ }^{41}$ In England, it is estimated that $£ 180$ million will be spent by the NHS on skin cancer by $2020 .^{42}$ In the USA, the annual economic burden of treating melanoma and KCs is US $\$ 8.1$ billion, increasing each year. ${ }^{2}$ Between $2002-$ 2006 and 2007-2011, growth in costs of melanoma and KCs alone was fivefold higher than for all other cancers and would be even higher if the full cost of treated benign skin tumours were also counted. For example, over 35.6 million actinic keratoses were treated in the US Medicare population in 2015 , increasing from 29.7 million in $2007 .^{43}$ Consequently, the scope for future cost savings to health economies through investment in skin cancer campaigns is considerable. ${ }^{35}$

The generalisability of these findings will be limited to settings resembling this study's, although the expected relativities of cost, intervention and quality of life effects should be proportional to country-specific skin cancer incidence. Some assumptions were necessary in our models, particularly regarding melanoma mortality rates in the early detection arm, since to date no relevant trials have been adequately powered to detect melanoma deaths. Reports of melanoma mortality after population screening for melanoma in Germany have been mixed. ${ }^{44}$ A further issue is the optimal frequency of skin checks since even annual checks may miss rapidly-growing nodular melanomas at a curable stage. For health utilities of multiple KCs and benign skin tumours where data are scarce, we used proxies and small disutility values for these events. We relied on self-reports of skin checks and sunscreen use from the QSKIN study and cannot rule out responder bias. Similarly, self-reported skin checks after melanoma diagnosis in a case control study ${ }^{6}$ may have been prone to recall bias and random misclassification, though the association between physician skin checks and thinner melanomas has been reported by others. ${ }^{7}$ Clinical skin examination frequency and outcomes were based on Janda $e t a l$ s 13 -month follow-up data but may vary in practice and therefore produce different numbers of skin malignancies in the early detection arm. ${ }^{16}$ Although the Nambour trial used SPF15+ sunscreen and our estimates may be conservative compared with sunscreen SPF30+, the effects of the very small difference in per cent UV filtered by SPF15+ vs $30+$ sunscreens ${ }^{45}$ would have been covered by our sensitivity analyses. Similarly, categorising thin melanomas as $<0.8 \mathrm{~mm}^{8}$ rather than $\leq 1 \mathrm{~mm}$, would not have changed relative differences observed across strategies. Finally, no indirect comparison analysis was undertaken between the randomised trials by Green et $a t^{4}$ and Janda et $a l^{16}{ }^{16}$ At baseline, study participants had similar proportions with fair skin $(56 \%$ in Green vs $62 \%$ 
in Janda) and sunscreen use (35\% in Green vs $33 \%$ in Janda). However, Green and Janda study participants differed by age (included 20-69year olds vs over 50 year olds), gender (men $43 \%$ vs $100 \%$ ) and previous history of skin cancers $(25 \%$ vs $71 \%)$, respectively.

These limitations should be set against the major strengths of this work, namely that we used data from two randomised controlled trials, thus minimising internal bias. We also relied on epidemiological and economic studies in the same general population, with the same ambient UV radiation levels and the same health system. We used melanoma diagnosis and mortality data from the Queensland Cancer Registry that is considered highly accurate and complete.

\section{CONCLUSION}

We have shown that primary prevention through daily use of sunscreen emerges as the priority for investment in the control of melanoma, and secondarily of $\mathrm{KC}$ and actinic keratoses in high-risk populations like Queensland's. As a corollary, there would be no long-term economic benefit in moving to implement whole body clinical skin examinations of people aged over 50 years to reduce the impact of melanoma. Further research is required to assess relative cost-benefit of early detection of melanoma in high risk subgroups versus prevention.

\section{Author affiliations}

${ }^{1}$ Department of Population Health, QIMR Berghofer Medical Research Institute, Brisbane, Queensland, Australia

${ }^{2}$ School of Nursing, Queensland University of Technology, Brisbane, Queensland, Australia

${ }^{3}$ School of Public Health, University of Queensland, Brisbane, Queensland, Australia ${ }^{4}$ Cancer Control Group, Department of Population Health, QIMR Berghofer Medical Research Institute, Herston, Queensland, Australia

${ }^{5}$ Centre of Health Services Research, Faculty of Medicine, University of Queensland, Brisbane, Queensland, Australia

${ }^{6}$ School of Public Health and Social Work, Institute for Health and Biomedical Innovation, Queensland University of Technology, Brisbane, Queensland, Australia ${ }^{7}$ CRUK Manchester Institute and Faculty of Biology Medicine and Health, The University of Manchester, Manchester, UK

\section{Twitter Louisa Gordon @louisagord}

Acknowledgements We gratefully thank Professor Andrew Searles from Hunter Medical Research Institute who reviewed an earlier draft of the manuscript.

Contributors $L G$ and $A G$ conceived the study aim and purpose. $L G$ undertook the main analyses with assistance from TME. CO, DCW, MJ and AG provided critical review of the study, contributed to drafting the paper and provided subject matter expertise. AG provided clinical and scientific expertise. All authors contributed to drafting the manuscript and reviewed the final version.

Funding The Skin Awareness Study was funded by National Health and Medical Research Council (NHMRC) Project grant \#497200. Follow-up of the Nambour Study was by NHMRC Grants \#199600 and \#974009. MJ is funded by a NHMRC TRIP Fellowship \#1151021.

Competing interests Author LG received conference travel, registration and accommodation for presenting a preliminary version of these findings at the 4th International UV and Skin Cancer Prevention Conference in May 2018 Toronto.

Patient consent for publication Not required.

Provenance and peer review Not commissioned; externally peer reviewed.

Data availability statement Data are available on reasonable request. Modelling files are available in TreeAge Pro software and are available on request to the authors.
Open access This is an open access article distributed in accordance with the Creative Commons Attribution Non Commercial (CC BY-NC 4.0) license, which permits others to distribute, remix, adapt, build upon this work non-commercially, and license their derivative works on different terms, provided the original work is properly cited, appropriate credit is given, any changes made indicated, and the use is non-commercial. See: http://creativecommons.org/licenses/by-nc/4.0/.

ORCID iDs

Louisa Gordon http://orcid.org/0000-0002-3159-4249

Catherine Olsen http://orcid.org/0000-0003-4483-1888

\section{REFERENCES}

1 IARC Globocan WHO. Cancer today interactive web tool, 2018. Available: http://gco.iarc.fr/today/home [Accessed 31 Aug 2018].

2 Guy GP, Machlin SR, Ekwueme DU, et al. Prevalence and costs of skin cancer treatment in the U.S., 2002-2006 and 2007-2011. Am J Prev Med 2015;48:183-7.

3 Luba MC, Bangs SA, Mohler AM, et al. Common benign skin tumors. Am Fam Physician 2003;67:729-38.

4 Green AC, Williams GM, Logan V, et al. Reduced melanoma after regular sunscreen use: randomized trial follow-up. J Clin Oncol 2011;29:257-63.

5 van der Pols JC, Williams GM, Pandeya N, et al. Prolonged prevention of squamous cell carcinoma of the skin by regular sunscreen use. Cancer Epidemiol Biomarkers Prev 2006;15:2546-8.

6 Aitken JF, Elwood M, Baade PD, et al. Clinical whole-body skin examination reduces the incidence of thick melanomas. Int $J$ Cancer 2010;126:450-8.

7 Olsen CM, Pandeya N, Thompson BS, et al. Physician skin checks before the diagnosis of melanoma correlate with tumor characteristics. J Invest Dermatol 2018;138:2288-91.

8 Gershenwald JE, Scolyer RA, Hess KR, et al. Melanoma staging: evidence-based changes in the American joint Committee on cancer eighth edition cancer staging manual. CA Cancer J Clin 2017;67:472-92.

9 Moynihan R, Doust J, Henry D. Preventing overdiagnosis: how to stop harming the healthy. BMJ 2012;344:e3502.

10 Waldmann A, Nolte S, Geller AC, et al. Frequency of excisions and yields of malignant skin tumors in a population-based screening intervention of 360,288 whole-body examinations. Arch Dermatol 2012;148:903-10.

11 Aitken JF, Janda M, Lowe JB, et al. Prevalence of whole-body skin self-examination in a population at high risk for skin cancer (Australia). Cancer Causes Control 2004;15:453-63.

12 Wolff T, Tai E, Miller T. Screening for skin cancer: an update of the evidence for the U.S. preventive services Task force. Ann Intern Med 2009;150:194-8.

13 Olsen CM, Thompson BS, Green AC, et al. Sun protection and skin examination practices in a setting of high ambient solar radiation: a population-based cohort study. JAMA Dermatol 2015;151:982-90.

14 Valery PC, Neale R, Williams G, et al. The effect of skin examination surveys on the incidence of basal cell carcinoma in a Queensland community sample: a 10-year longitudinal study. J Investig Dermatol Symp Proc 2004;9:148-51.

15 van der Pols JC, Williams GM, Neale RE, et al. Long-term increase in sunscreen use in an Australian community after a skin cancer prevention trial. Prev Med 2006;42:171-6.

16 Janda M, Youl P, Neale R, et al. Clinical skin examination outcomes after a video-based behavioral intervention: analysis from a randomized clinical trial. JAMA Dermatol 2014;150:372-9.

17 Carter HE, Schofield DJ, Shrestha R. The productivity costs of premature mortality due to cancer in Australia: evidence from a Microsimulation model. PLoS One 2016;11:e0167521.

18 Queensland Cancer Statistics On-Line. Viertel cancer research centre, based on data released by the Queensland cancer registry (1982-2014 released January 2017) Brisbane, Australia: cancer Council Queensland, 2017. Available: qcsol.cancerqld.org.au [Accessed 12 Aug 2018].

19 Wolchok JD, Rollin L, Larkin J. Nivolumab and ipilimumab in advanced melanoma. N Engl J Med 2017;377:2503-4.

20 Australian Bureau of Statistics. Life tables 2015-2017. Canberra: Commonwealth of Australia, 2018.

21 Aitken JF, Janda M, Elwood M, et al. Clinical outcomes from skin screening clinics within a community-based melanoma screening program. J Am Acad Dermatol 2006;54:105-14.

22 Pandeya N, Olsen CM, Whiteman DC. The incidence and multiplicity rates of keratinocyte cancers in Australia. Med J Aust 2017;207:339-43. 
23 Aitken JF, Youlden DR, Baade PD, et al. Generational shift in melanoma incidence and mortality in Queensland, Australia, 19952014. Int J Cancer 2018;142:1528-35.

24 Darlington S, Williams $\mathrm{G}$, Neale $\mathrm{R}$, et al. A randomized controlled trial to assess sunscreen application and beta carotene supplementation in the prevention of solar keratoses. Arch Dermatol 2003;139:451-5.

25 Gordon LG, Elliott TM, Olsen CM, et al. Multiplicity of skin cancers in Queensland and their cost burden to government and patients. Aust N Z J Public Health 2018;42:86-91.

26 Youlden DR, Baade PD, Soyer HP, et al. Ten-Year survival after multiple invasive melanomas is worse than after a single melanoma: a population-based study. J Invest Dermatol 2016;136:2270-6.

27 Helgadottir $\mathrm{H}$, Tuominen $\mathrm{R}$, Olsson $\mathrm{H}$, et al. Cancer risks and surviva in patients with multiple primary melanomas: association with family history of melanoma and germline CDKN2A mutation status. J Am Acad Dermatol 2017;77:893-901.

28 Tran AD, Fogarty G, Nowak AK, et al. A systematic review and meta-analysis of utility estimates in melanoma. $\mathrm{Br} J$ Dermatol 2018;178:384-93.

29 Gaulin C, Sebaratnam DF, Fernández-Peñas P. Quality of life in nonmelanoma skin cancer. Australas J Dermatol 2015;56:70-6.

30 Seidler AM, Bramlette TB, Washington CV, et al. Mohs versus traditional surgical excision for facial and auricular nonmelanoma skin cancer: an analysis of cost-effectiveness. Dermatol Surg 2009;35:1776-87.

31 Streeton CL, Gospodarevskaya E, Harris AH. How are solar keratoses treated by general practitioners in Australia? Int $J$ Dermatol 2006;45:272-6.

32 Harris $\mathrm{AH}$, Hill SR, Chin G, et al. The role of value for money in public insurance coverage decisions for drugs in Australia: a retrospective analysis 1994-2004. Med Decis Making 2008;28:713-22.

33 Briggs $\mathrm{AH}$, Weinstein MC, Fenwick EAL, et al. Model parameter estimation and uncertainty: a report of the ISPOR-SMDM Modeling Good Research Practices Task Force-6. Value Health 2012;15:835-42.

34 Eddy DM, Hollingworth W, Caro JJ, et al. Model transparency and validation: a report of the ISPOR-SMDM Modeling Good Research Practices Task Force-7. Value Health 2012;15:843-50.
35 Gordon LG, Rowell D. Health system costs of skin cancer and costeffectiveness of skin cancer prevention and screening: a systematic review. Eur J Cancer Prev 2015;24:141-9.

36 Pil L, Hoorens I, Vossaert K, et al. Cost-effectiveness and budget effect analysis of a population-based skin cancer screening. JAMA Dermatol 2017;153:147-53.

37 Wilson ECF, Usher-Smith JA, Emery J et al. A modeling study of the cost-effectiveness of a risk-stratified surveillance program for melanoma in the United Kingdom. Value Health 2018;21:658-68.

38 Gordon LG, Brynes J, Baade PD, et al. Cost-Effectiveness analysis of a skin awareness intervention for early detection of skin cancer targeting men older than 50 years. Value Health 2017;20:593-601.

39 Watts CG, Cust AE, Menzies SW, et al. Cost-Effectiveness of skin surveillance through a specialized clinic for patients at high risk of melanoma. J Clin Oncol 2017;35:63-71.

40 Green A, Leslie D, Weedon D. Diagnosis of skin cancer in the general population: clinical accuracy in the Nambour survey. Med J Aust 1988;148:447-50.

41 Gordon LG, Scuffham PA, van der Pols JC, et al. Regular sunscreen use is a cost-effective approach to skin cancer prevention in subtropical settings. J Invest Dermatol 2009;129:2766-71.

42 Vallejo-Torres L, Morris S, Kinge JM, et al. Measuring current and future cost of skin cancer in England. J Public Health 2014;36:140-8.

43 Yeung $\mathrm{H}$, Baranowski ML, Swerlick RA, et al. Use and cost of actinic keratosis destruction in the Medicare Part B fee-for-service population, 2007 to 2015. JAMA Dermatol 2018;154:1281.

44 Eisemann N, Waldmann A, Holleczek B, et al. Observed and expected mortality in the German skin cancer screening pilot project screen. J Med Screen 2018;25:166-8.

45 Nijsten T. Sunscreen use in the prevention of melanoma: common sense rules. J Clin Oncol 2016;34:3956-8.

46 Elliott TM, Whiteman DC, Olsen CM, et al. Estimated Healthcare Costs of Melanoma in Australia Over 3 Years Post-Diagnosis. Appl Health Econ Health Policy 2017:15:805-16.

47 Reeve R, Srasuebkul P, Langton JM, et al. Health care use and costs at the end of life: a comparison of elderly Australian decedents with and without a cancer history. BMC Palliat Care $2018 ; 17$. 